\title{
KENAMPAKAN FISIK KOTA DAN DAERAH PERI URBAN SURAKARTA
}

\author{
Nur Aini Amalia Mataufani ${ }^{1}$, Paramita Rahayu ${ }^{1}$, Erma Fitria Rini ${ }^{1}$ \\ ${ }_{1}$ Program Studi Perencanaan Wilayah dan Kota, Fakultas Teknik, Universitas Sebelas Maret
}

\begin{abstract}
Abstrak
Perkembangan suatu kota dapat menimbulkan dampak pada wilayah sekitarnya terutama wilayah pinggirannya (peri urban). Kota Surakarta adalah salah satu kota yang mengalami perkembangan sangat pesat, akan tetapi perkembangan ini tidak sebanding dengan ketersediaan lahan yang ada, akibatnya kenampakan fisik kekotaan meluas pada wilayah peri urban. Kenampakan fisik ini akan membentuk pola morfologi tertentu. Morfologi dapat diartikan sebagai kenampakan fisik yang terdiri dari tiga komponen yaitu penggunaan lahan, pola jaringan jalan, dan pola bangunan. Tujuan penelitian ini adalah untuk mengetahui pola morfologi Kota Surakarta dan wilayah peri urban dengan meninjau komponen morfologi yang ada di dalamnya. Penelitian ini menggunakan metode deskriptif dengan tiga tahap yaitu mengidentifikasi wilayah peri urban Kota Surakarta, mengidentifikasi komponen morfologi pada Kota Surakarta dan wilayah peri urban dan mengidentifikasi pola morfologi yang terbentuk. Wilayah peri urban diidentifikasi berdasarkan kriteria karakteristik wilayah peri urban, yang selanjutnya akan dilihat komponen morfologi di dalamnya. Hasil penelitian, menunjukkan bahwa Kota Surakarta dan wilayah peri urban memiliki kesamaan pada dominasi penggunaan lahan dan pola jaringan jalan, tetapi terdapat perbedaan pada tekstur kawasan. Dominasi penggunaan lahan adalah berupa permukiman dan pola jaringan jalan adalah berupa pola grid. Tekstur kawasan yang teridentifikasi pada Kota Surakarta adalah homogen, sedangkan pada wilayah peri urban adalah heterogen. Hal ini disebabkan oleh masih tersedianya ruang terbuka hijau berupa sawah dan tegalan pada wilayah peri urban. Dari hasil analisis kondisi eksisting pada ketiga komponen, menunjukkan bahwa terdapat perbedaan pola pada Kota Surakarta dan wilayah peri urban. Kota Surakarta memiliki pola bujur sangkar sedangkan wilayah peri urbannya cenderung pada pola pita.
\end{abstract}

Kata kunci: Kota Surakarta; pola morfologi; wilayah peri urban

\begin{abstract}
The development of a city as a core of a region will impact its surrounding area, especially urban fringe. . Surakarta is one of the cities that experiencing rapid urban development. However, as the land area of the city is limited, such rapid development expands to the surrounding regions. . This physical development will create certain morphological patterns. Morphology can be interpreted as a physical appearance consisting of three components, namely land use, road patterns, and building patterns. This study aims at investigating the morphological patterns of Surakarta and its peri-urban area by ridentifying its morphological components. This study is conducted in three steps of analysis,, first, identifying the peri-urban areas of Surakarta, second, recognizing the morphological components in Surakarta City and its peri-urban area and lastly, identifying the formation of morphological patterns. The peri-urban areas is identified based on its characteristics and then will be used to identify the morphological components. The result shows that Surakarta and its peri-urban areas has to some extent similarities in the dominant land use and road pattern, while difference exist in the texture of the two areas, city and peri-urban. The dominant land use of Surakarta and the peri-urban area is settlement and the road patterns identified are grid patterns. The texture of the area of Surakarta is homogeneous, while the textureof the peri-urban area is tend to show a heterogeneous pattern. This is caused by the mixed of built up area and open space in the peri-urban. The analysis of these three components show that Surakarta tend to be able to be categorized as having a square pattern while the peri-urban areas tend to comply with ribbon pattern criteria.
\end{abstract}

Keywords: morphological patterns; Surakarta City; urban fringe area

\section{PENDAHULUAN}

Kota identik dengan perkembangan pesat kawasan terbangun. Kota Surakarta merupakan salah satu kota di Jawa Tengah yang memiliki perkembangan cukup pesat (Kurnianingsih \& Rudiarto, 2014). Perkembangan kota yang pesat tentu akan berdampak pada peningkatan kebutuhan lahan untuk mewadahi perkembangan tersebut. Ketersediaan lahan semakin 
berkurang karena jumlah kebutuhan dan permintaan akan lahan sendiri semakin meningkat. Perkotaan sudah tidak memiliki ketersediaan lahan yang cukup untuk memenuhi kebutuhan aktivitas masyarakat. Selain itu, pertambahan penduduk sejalan dengan perkembangan kota. Hal inilah yang menjadikan wilayah pinggiran kota mendapatkan imbas dari perkembangan kota yang pesat. Wilayah peri urban ditandai dengan adanya perubahan lahan non terbangun menjadi lahan terbangun sehingga menyebabkan rembetan kenampakan fisik kekotaan pada wilayah peri urban.

Kota Surakarta merupakan salah satu kota yang perkembangannya sangat pesat dibandingkan kota-kota lain di Jawa Tengah. Salah satu penyebabnya adalah adanya kelengkapan sarana prasarana di Kota Surakarta. Hal ini tentunya menimbulkan dampak bagi wilayah sekitar terutama wilayah pinggirannya (peri urban). Daerah ini secara alami terbentuk dari perkembangan dan rembetan yang terjadi pada kota (Jati \& Christanto, 2012). Perkembangan kota ini mulai mengarah ke wilayah pinggirannya, hal ini ditandai dengan adanya sarana-sarana perkotaan berupa hotel, pusat perbelanjaan, kantorkantor pemerintahan, rumah sakit, ruko-ruko dan lain-lain. Adanya sarana-sarana tersebut, dampak perkembangan kota terhadap wilayah pinggiran atau peri urban semakin besar. Wilayah peri urban sebagai wilayah yang terdampak dari perkembangan Kota Surakarta mengalami perkembangan wilayah dan membentuk pola yang juga berkaitan dengan pola kota satellitnya.

Morfologi merupakan kenampakan fisik kawasan yang ditinjau dari struktur yang membentuk bentuk kenampakan tertentu (Putri, Rahayu, \& Putri, 2016). Menurut Yunus (2008), kenampakan fisik kawasan memiliki berbagai macam bentuk. Bentukbentuk ini teridentifikasi dari tiga komponen utama morfologi yaitu penggunaan lahan, pola jaringan jalan dan pola bangunan. Perkembangan pada wilayah peri urban yang merupakan dampak dari kota cenderung memiliki pola yang tidak terprediksi. Pola yang tidak terprediksi ini nantinya akan menimbulkan masalah terutama terkait perencanaan pembangunan di masa yang akan datang. Maka dari itu perlu dikaji bagaimana pola yang terbentuk pada Kota Surakarta dan wilayah peri urbannya.

\section{KAJIAN LITERATUR}

\subsection{PERI URBAN}

Wilayah peri urban merupakan wilayah yang letaknya di luar batas administrasi kota yang ditandai dengan proses pertambahan luas lahan terbangun (Yunus, 2008). Wilayah peri urban adalah zona transisi antara kota dan desa yang memiliki karakteristik unik dengan kepadatan yang tinggi dan aktivitas yang beraneka ragam (Kurnianingsih \& Rudiarto, 2014). Menurut Giyarsih, (2009) dalam Hardati (2011) wilayah peri urban adalah wilayah-wilayah perdesaan di koridor antar kota yang mengalami transformasi struktur wilayah. Menurut Subroto dan Setyadi, (1997) dalam Hardati, (2011) urban fringe adalah daerah transisi, bukan daerah antara desa dan kota, namun daerah perdesaan yang menyatu dengan daerah perkotaan yang diwarnai oleh disparitas karakter desa dan kota yang kuat baik secara fisik spasial dan sosio kultural. Urban fringe merupakan wilayah irisan antar kota, desa dan area dengan pertumbuhan yang relatif cepat (Krismasta, Rogi, \& Tilaar, 2014). Menurut Pryor, (1968) dalam Krismata (2014) wilayah peri urban adalah wilayah peralihan mengenai penggunaan lahan, karakteristik sosial dan demografis, serta wilayah ini terletak antara lahan kekotaan kompak terbangun yang menyatu dengan pusat kota dan lahan kedesaan yang disana hampir tidak ditemukan bentuk-bentuk lahan kekotaan dan permukiman perkotaan. Wilayah peri urban diakibatkan oleh proses ekspansi kota ke wilayah pinggiran yang berakibat pada perubahan fisikal misal perubahan tata guna lahan, demografi, keseimbangan ekologis serta kondisi sosial ekonomi (Sushanti, Imansyah, Susanti, Mahendra, \& Ridha, 2018). Dari berbagai definisi wilayah peri urban, dilakukan sintesis teori karakteristik wilayah peri urban yang menjadi kriteria dalam delineasi wilayah pada penelitian ini. Empat kriteria wilayah peri urban adalah sebagai berikut:

a) Wilayah yang berada di luar batas administrasi kota resmi/kota induk,

b) Wilayah yang memiliki kepadatan penduduk lebih rendah dari kota resmi/kota induk (dalam penelitian ini adalah Kota Surakarta), tetapi lebih tinggi di antara wilayah di dalamnya,

c) Wilayah yang memiliki luas penggunaan lahan terbangun lebih dari $75 \%$ dari luas wilayahnya

d) Wilayah yang mengalami peningkatan jumlah penduduk dalam jangka waktu tertentu. 


\subsection{MORFOLOGI}

Menurut Yunus (2000) bentuk morfologi dibedakan menjadi bentuk kompak dan bentuk tidak kompak. Bentuk kompak meliputi bentuk bujur sangkar, empat persegi panjang, bulat, kipas, pita, dan gurita. Bentuk tidak kompak meliputi bentuk terpecah, berantai, terbelah, tidak berpola dan stellar. Menurut Hudson, (1972) dalam Yunus, (2000; 110) terdapat tujuh bentuk kenampakan fisik atau morfologi antara lain satelit atau pusat baru, radial, cincin, liniear bermanik, kompak, memancar dan bentuk kota di bawah tanah. Sedangkan menurut Russwurm (1980) dalam Yunus (2000; 110) hanya terdapat empat bentuk yaitu, konsentris, konstelasi, memanjang dan terserak. Empat bentuk tersebut mengalami perubahan karena adanya perkembangan waktu dan perubahan-perubahan fisikal lainnya. Bentuk morfologi yang digunakan pada penelitian ini adalah bentuk morfologi menurut Yunus (2000) yaitu bentuk bujur sangkar, empat persegi panjang, bulat, kipas, pita, gurita, terpecah, berantai, terbelah, tidak berpola dan stellar.

Pada Tabel 1 dapat dilihat indikator bentuk morfologi menurut Yunus (2000) yang digunakan pada penelitian ini.

Tabel 1. Komponen Bentuk Morfologi

\begin{tabular}{|c|c|}
\hline Bentuk morfologi & Indikator/parameter \\
\hline Bujur sangkar & $\begin{array}{ll}\text { - } & \text { Perluasan ke segela arah } \\
\text { - } & \text { Pertumbuhan pesat pada jalur transportasi } \\
\text { - } & \text { Penggunaan lahan pada pusat berupa perdagangan dan jasa, sisanya permukiman } \\
\text { - } & \text { Pola jaringan jalan berupa pola radial konsentris dan grid } \\
\text { - } & \text { Pola bangunan; homogen dengan kerapatan merata }\end{array}$ \\
\hline $\begin{array}{l}\text { Empat persegi } \\
\text { panjang }\end{array}$ & $\begin{array}{l}\text { - Pola jaringan jalan berupa linear dan grid } \\
\text { - } \quad \text { Pola bangunan; tersebar dengan pola memanjang (homogen), kerapatan tersebar }\end{array}$ \\
\hline Kipas & $\begin{array}{ll}\text { - } & \text { Perkembangan yang mengarah dari luar relatif seimbang } \\
\text { - } & \text { Pola jaringan jalan berupa grid dan radial konsentris } \\
\text { - } & \text { Pola bangunan; tersebar ke berbagai arah (homogen) dengan kerapatan seimbang } \\
\text { - } & \text { Biasa terjadi pada daerah pelabuhan perairan (delta sungai) dan pegunungan }\end{array}$ \\
\hline Bulat & $\begin{array}{l}\text { - } \quad \text { Perkembangan ke arah luar seimbang } \\
\text { - } \quad \text { Pola jaringan jalan berupa radial konsentris ke segala arah } \\
\text { - }\end{array}$ \\
\hline Pita & $\begin{array}{ll}\text { - } & \text { Pola jaringan jalan berupa linear dan grid } \\
\text { - } & \text { Pola bangunan; heterogen, kerapatan tidak teratur } \\
\text { - } & \text { Jalur transportasi memberikan pengaruh }\end{array}$ \\
\hline Gurita & $\begin{array}{l}\text { - Penggunaan lahan beragam dengan pusat kawasan memiliki fungsi lebih kompleks dibandingkan } \\
\text { - } \quad \text { Pawasan lainnya } \\
\text { - } \quad \text { Pola bangan janan mengikuti pola jalan ke beberapa arah } \\
\text { - } \quad \text { Pola bangunan; heterogen dengan kerapatan terpusat tinggi }\end{array}$ \\
\hline Tidak berpola & $\begin{array}{ll}\text { - } & \text { Pola jaringan jalan radial konsentris, grid, dan tidak berpola } \\
\text { - } & \text { Pola bangunan; heterogen dengan kerapatan tidak beraturan }\end{array}$ \\
\hline Terpecah & $\begin{array}{ll}\text { - } & \text { Dikelilingi areal pertanian } \\
\text { - } & \text { Dihubungkan jalur transportasi }\end{array}$ \\
\hline Berantai & $\begin{array}{l}\text { - } \quad \text { Lahan terbangun dan non terbangun dipisahkan jalur transportasi } \\
\text { - } \quad \text { Pola jaringan jalan linear dan grid } \\
\text { - } \quad \text { Pola bangunan; heterogen }\end{array}$ \\
\hline Terbelah & $\begin{array}{ll}\text { - } & \text { Dibelah oleh perairan cukup lebar } \\
\text { - } & \text { Pola jaringan jalan ke segala arah } \\
\text { - } & \text { Pola bangunan; heterogen dengan kerapatan menyebar bervariasi }\end{array}$ \\
\hline Stellar & $\begin{array}{ll}\text { - } & \text { Terdapat pada kota besar yang di kelilingi kota satelit } \\
\text { - } & \text { Pusat kawasan menyebar } \\
\text { - } & \text { Pola jaringan jalan radial konsentris } \\
\text { - } & \text { Kawasan pusat dan sub pusat terpisahkan lahan non terbangun }\end{array}$ \\
\hline
\end{tabular}

Sumber : Yunus, 2000 
Morfologi memiliki tiga komponen dalam mencermati kondisi fisik kawasan. Komponen tersebut ditinjau dari penggunaan lahan kawasan yang mencerminkan aktivitas kawasan, pola sirkulasi atau pola jaringan jalan yang menghubungkan antar kawasan, dan pola bangunan beserta fungsinya (Soetomo, 2009). Menurut Smailes dalam Astutik, Tallo, \& Pratiwi, (2014), tiga komponen yang digunakan sebagai pembentuk fisik keruangan atau morfologi kawasan adalah penggunaan lahan, polapola jalan dan tipe-tipe bangunan Dari beberapa definisi tersebut didapatkan tiga variabel penelitian berupa penggunaan lahan, pola jaringan jalan dan pola bangunan. Pada setiap bentuk terdapat indikator komponen morfologi yang menjadi dasar dalam menentukan bentuk morfologi. Indikator setiap bentuk pada tiap-tiap komponen dapat dilihat pada Tabel 2.

Tabel 2. Komponen Bentuk Morfologi

\begin{tabular}{|c|c|c|}
\hline Variabel & Bentuk & Indikator \\
\hline Penggunaan & Bujur sangkar & Penggunaan lahan pada pusat berupa perdagangan dan jasa, sisanya permukiman \\
\hline \multirow[t]{5}{*}{ Lahan } & Gurita & $\begin{array}{l}\text { - Penggunaan lahan beragam memiliki fungsi lebih kompleks dibandingkan kawasan } \\
\text { lainnya di sepanjang jalan }\end{array}$ \\
\hline & Terpecah & - $\quad$ Areal pertanian mengelilingi kawasan \\
\hline & Berantai & - Lahan terbangun dan non terbangun dipisahkan jalur transportasi \\
\hline & Terbelah & - Dibelah oleh perairan cukup lebar \\
\hline & Stellar & - $\quad$ Terdapat beberapa sub kawasan \\
\hline \multirow[t]{14}{*}{$\begin{array}{l}\text { Pola jaringan } \\
\text { jalan }\end{array}$} & Bujur sangkar & $\begin{array}{ll}- & \text { Radial konsentris } \\
\text { - } & \text { Grid }\end{array}$ \\
\hline & Empat persegi panjang & - $\quad$ Linear atau grid \\
\hline & Kipas & $\begin{array}{ll}- & \text { Radial konsentris } \\
\text { - } & \text { Grid }\end{array}$ \\
\hline & Bulat & - $\quad$ Radial konsentris (ke segala arah) \\
\hline & Pita & - Linear atau grid \\
\hline & Gurita & - $\quad$ Radial konsentris \\
\hline & & - Grid \\
\hline & Tidak berpola & - $\quad$ Radial konsentris \\
\hline & & - Grid \\
\hline & & - $\quad$ Tidak berpola \\
\hline & Terpecah & - $\quad$ Radial konsentris \\
\hline & Berantai & - Linear atau grid \\
\hline & Terbelah & - Tidak berpola (ke segala arah) \\
\hline & Stellar & - Radial konsentris \\
\hline Pola & Bujur sangkar & - Homogen, kerapatan merata \\
\hline \multirow[t]{10}{*}{ Bangunan } & Empat persegi panjang & - Tersebar dengan pola memanjang (homogen), kerapatan tersebar \\
\hline & Kipas & - Tersebar ke berbagai arah (homogen), kerapatan seimbang \\
\hline & Bulat & - Homogen, persebaran seimbang \\
\hline & Pita & - Heterogen, kerapatan tidak teratur \\
\hline & Gurita & - Heterogen, kerapatan terpusat tinggi \\
\hline & Tidak berpola & - Heterogen, kerapatan tidak beraturan \\
\hline & Terpecah & - Homogen, kerapatan tidak beraturan \\
\hline & Berantai & - Heterogen \\
\hline & Terbelah & - Heterogen, kerapatan menyebar bervariasi \\
\hline & Stellar & - Heterogen, kerapatan terpusat \\
\hline
\end{tabular}

Sumber : Tyas et al, 2013; Yunus, 2000

\section{METODE PENELITIAN}

Metode dalam penelitian ini adalah metode deskriptif. Menurut Sugiyono (2010) metode deskriptif berusaha menggambarkan dan menginterpretasikan objek sesuai dengan keadaan yang ada. Pembatasan substansi yang dibahas dalam penelitian adalah komponen dan pola morfologi. Komponen morfologi antara lain adalah penggunaan lahan, pola jaringan jalan dan pola bangunan.

Pengambilan data dilakukan dengan dua cara yaitu survei data primer berupa observasi pada kawasan dan survei data sekunder berupa beberapa data instansi guna menunjang data primer. Data sekunder yang digunakan antara lain tabel 
kecamatan dalam angka (tahun 2013 dan tahun 2018) yang digunakan untuk delineasi wilayah peri urban. Kemudian setelah wilayah peri urban teridentifikasi, peta citra satelit dan tabel jaringan jalan digunakan sebagai acuan survei data primer komponen morfologi. Hasil survei yang didapatkan berupa peta penggunaan lahan, proporsi penggunaan lahan, peta pola jaringan jalan, dan peta pola bangunan yang kemudian dideskripsikan. Teknik analisis pola morfologi dilakukan dengan melihat hasil survei dan indikator pola morfologi. Sehingga dapat disimpulkan pola yang terbentuk dari komponen yang teridentifikasi. Untuk alur penelitian dapat dilihat pada Gambar 1.

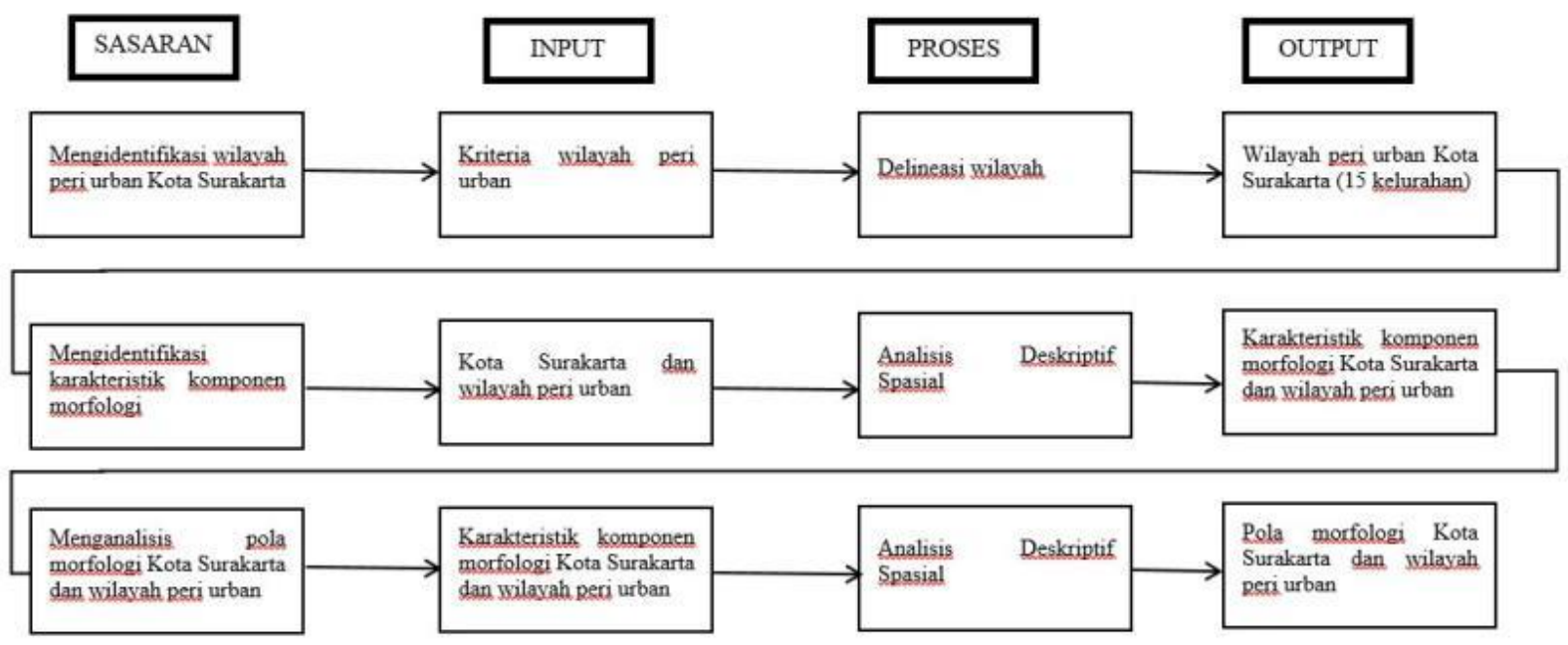

Gambar 1. Kerangka Analisis Penelitian

\section{HASIL DAN PEMBAHASAN}

\subsection{IDENTIFIKASI WILAYAH PERI URBAN KOTA SURAKARTA}

Dalam penelitian ini Kota Surakarta berperan sebagai kota yang akan dilihat bagaimana perkembangan dan pengaruhnya terhadap wilayah di sekitarnya atau disebut juga wilayah peri urban. Wilayah peri urban Kota Surakarta memiliki beberapa bagian dengan karakteristik masing-masing. Pada wilayah peri urban Kota Surakarta terdapat sarana berskala regional seperti sarana kesehatan berupa rumah sakit, sarana pendidikan berupa universitas, sarana perdagangan komersil berupa mall serta dilalui simpul-simpul transportasi berupa jaringan jalan primer seperti Jalan Ahmad Yani (Jalan Semarang-Solo) dan jaringan jalan sekunder yaitu Jalan Adi Sumarmo, Jalan Baki-Solo, Jalan Raya Pajang, Jalan Ir. Soekarno dan Jalan Brigjen Sudiarto. Serta pembangunan industri-industri yang terdapat pada wilayah peri urban dan fasilitas kota yang terletak di wilayah peri urban yaitu Bandara Adi Soemarmo. Hal ini menunjukkan bahwa adanya konektivitas sangat tinggi antara kota induk dan wilayah peri urban. Dikarenakan keterbatasan wilayah pada kota induk, wilayah peri urban menjadi pilihan terbaik untuk menyokong berkembangnya suatu kota. Karena letaknya yang tidak jauh dari kota induk, potensi paling besar dalam terkena dampak perkembangan kota sangat besar, didukung dengan adanya faktor-faktor pendukung lain seperti ketersediaan lahan, keterjangkauan harga, keterjangkauan jarak menuju pusat kota, serta ketersediaan fasilitas-fasilitas pendukung perkotaan.

Identifikasi wilayah peri urban Kota Surakarta dilakukan melalui delineasi dengan empat kriteria karakteristik wilayah peri urban yang didapatkan melalui sintesis teori. Kriteria pertama adalah wilayah yang berada di luar batas administrasi kota diasumsikan menjadi wilayah yang berbatasan langsung dengan Kota Surakarta. Batasan wilayah yang digunakan adalah skala kecamatan. Pada kriteria pertama, terdapat sembilan kecamatan yang teridentifikasi berbatasan langsung dengan Kota Surakarta. Kriteria kedua adalah kawasan yang memiliki kepadatan lebih rendah dari kota resmi, namun lebih tinggi di antara wilayah di dalamnya. Data yang digunakan pada kriteria kedua adalah data kecamatan dalam angka tahun 2018 dengan batasan wilayah berupa kelurahan. Kota resmi yang dimaksudkan adalah Kota Surakarta dan wilayah di dalamnya yang dimaksudkan adalah wilayah yang masuk ke dalam kriteria pertama yaitu 113 kelurahan. Pada kriteria kedua dapat terlihat kepadatan penduduk wilayah peri urban mengarah ke bagian Barat dan bagian Selatan Kota Surakarta. Hal ini ditunjukkan dengan kepadatan penduduk skala sedang dan tinggi yang berada pada kedua bagian wilayah peri urban Kota Surakarta. 
Kriteria ketiga adalah luas penggunaan lahan terbangun lebih dari 75\% dari luas wilayah (BPS Kab. Boyolali, 2018; BPS Kab. Karanganyar, 2018; BPS Kab. Sukoharjo, 2018). Pada kriteria ketiga, terlihat perbedaan arah dari kriteria kedua. Jika pada kriteria kedua wilayah peri urban Kota Surakarta mengarah pada wilayah bagian Selatan menuju ke Barat, pada kriteria ketiga wilayah peri urban Kota Surakarta mengarah pada wilayah bagian Utara, Barat dan Selatan. Data yang diambil adalah data luas wilayah bukan sawah dan wilayah sawah. Luas bukan sawah disini diasumsikan sebagai luas lahan terbangun. Apabila kelurahan tersebut memiliki luas bukan sawah melebihi $75 \%$ dari luas wilayah maka kelurahan tersebut masuk ke dalam kriteria ketiga. Kriteria keempat adalah terjadinya peningkatan jumlah penduduk dalam jangka waktu tertentu (BPS Kab. Boyolali, 2013, 2018; BPS Kab. Karanganyar, 2014, 2018; BPS Kab. Sukoharjo, 2014, 2018). Delineasi keempat kriteria wilayah peri urban dapat dilihat pada Gambar 2.

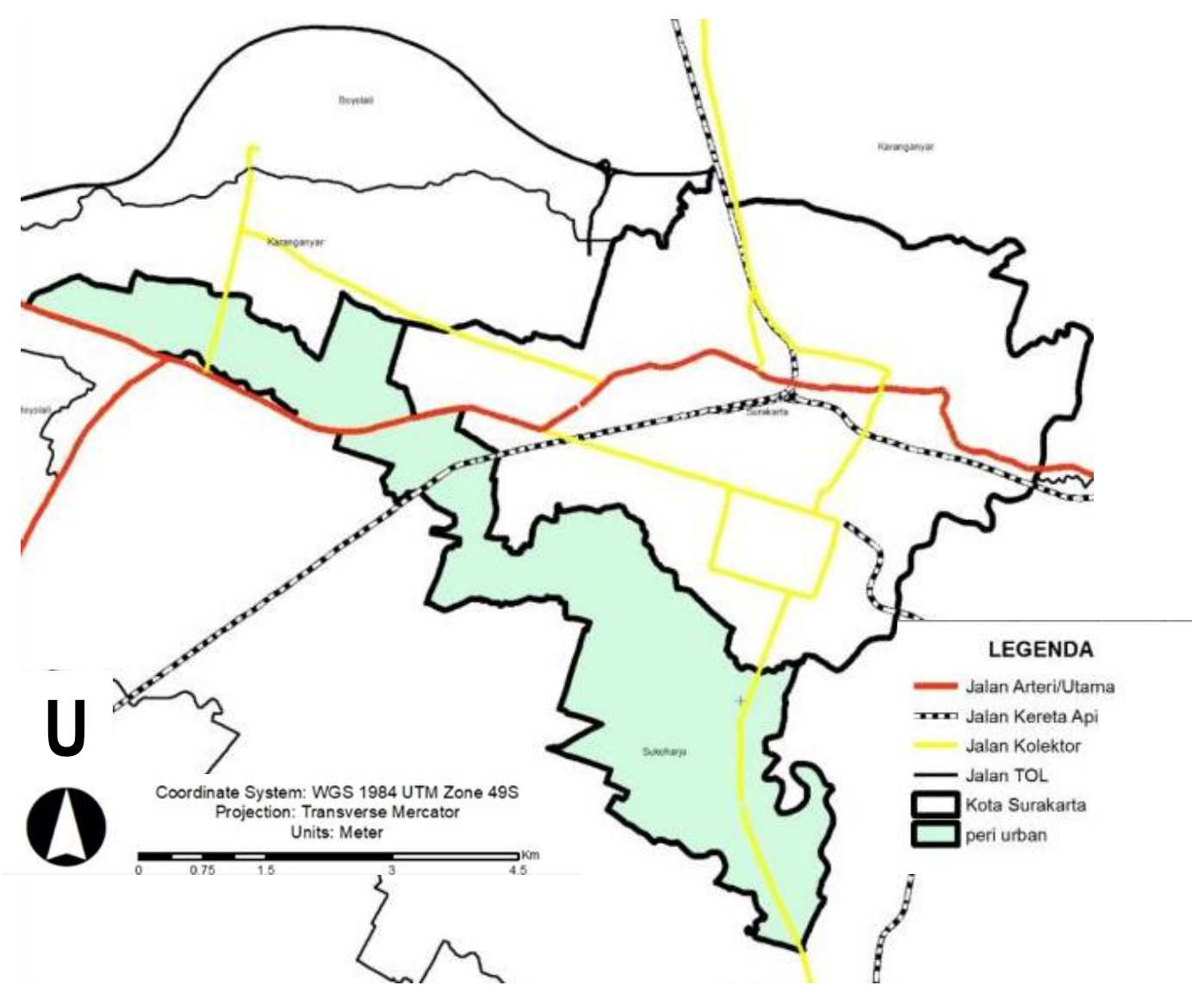

Gambar 2. Delineasi Wilayah Peri Urban Kota Surakarta

Dari delineasi peta, didapatkan 15 kelurahan yang memenuhi keempat kriteria wilayah peri urban. Dari 15 kelurahan ini nantinya akan dilihat komponen pembentuk morfologi di dalamnya guna mendukung teridentifikasinya pola morfologi Kota Surakarta dan wilayah peri urban di sekitarnya. Kota Surakarta tidak dapat berdiri sendiri sebagai kota induk dikarenakan membutuhkan peran wilayah peri urban untuk menyokongnya juga dikarenakan perkembangan pesat pada wilayah peri urban yang terkena dampak dari perkembangan Kota Surakarta itu sendiri. Dari kriteria kedua hingga keempat, wilayah peri urban Kota Surakarta bagian Timur tidak terlalu mengalami perkembangan. Hal ini dilihat dari arah condongnya kelurahan-kelurahan yang memenuhi kriteria wilayah peri urban. Sedangkan wilayah peri urban bagian Utara, dapat dibilang masih mengalami perkembangan karena pada kriteria ketiga perkembangan wilayah peri urban Kota Surakarta juga mengarah ke bagian Utara. Untuk wilayah peri urban bagian Selatan dan Barat, sebagian besar kelurahan memenuhi kriteria. Maka dari itu wilayah peri urban yang terpilih adalah 15 kelurahan yang terdiri dari sebagian Kecamatan Kartasura dan sebagian Kecamatan Grogol. 


\subsection{IDENTIFIKASI KOMPONEN MORFOLOGI}

Data penggunaan lahan eksisting didapatkan dari survei data primer berupa observasi pada Kota Surakarta dan wilayah peri urban guna melengkapi data sekunder berupa citra satelit. Pada penggunaan lahan eksisting ini dapat dilihat persebaran penggunaan lahan pada Kota Surakarta dan wilayah peri urbannya. Penggunaan lahan eksisting pada Kota Surakarta dan wilayah peri urban (dapat dilihat pada Gambar 3) teridentifikasi terdiri atas lima penggunaan lahan yaitu permukiman, perdagangan \& jasa, industri, ruang terbuka hijau (RTH), dan lain-lain.

Permukiman mendominasi penggunaan lahan baik itu pada Kota Surakarta maupun wilayah peri urbannya. Dapat dilihat dari Gambar 3 yang merupakan peta penggunaan lahan eksisting Kota Surakarta dan wilayah peri urban, warna kuning hampir memenuhi sebagian besar wilayah Kota Surakarta dan wilayah peri urban. Dominasi penggunaan lahan permukiman pada wilayah peri urban lebih cenderung berada pada wilayah peri urban bagian Barat. Pada wilayah peri urban bagian Selatan lebih cenderung pada penggunaan lahan industri serta ketersediaan ruang terbuka hijau berupa sawah dan tegalan, tetapi penggunaan lahan permukiman juga cukup mendominasi. Pada Kota Surakarta bagian Utara terlihat masih terdapat beberapa bagian ruang terbuka hijau, berbeda dengan bagian Selatan yang sudah didominasi dengan permukiman.

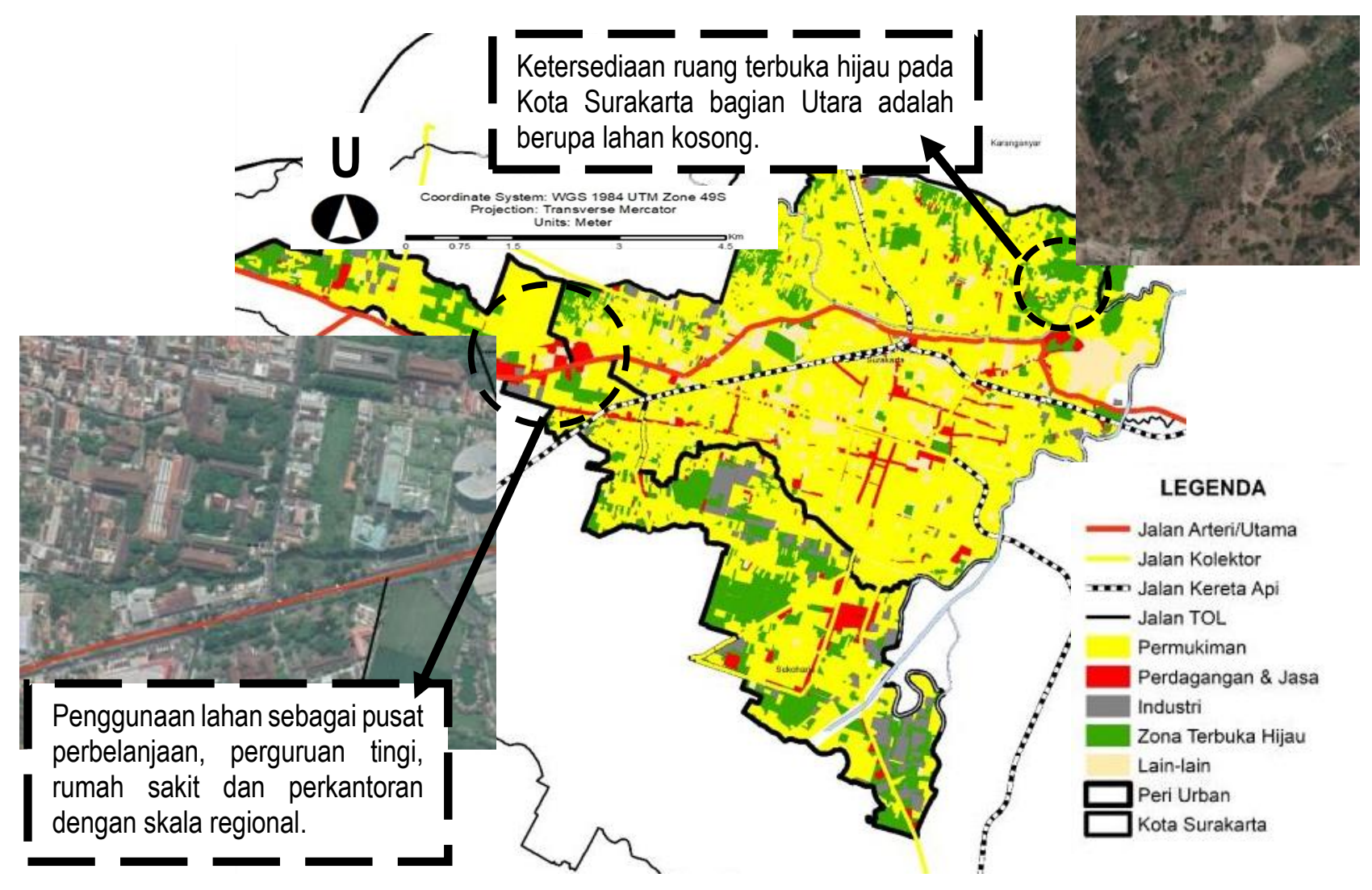

Gambar 3. Penggunaan Lahan Eksisting Kota Surakarta dan Wilayah Peri Urban

Pola jaringan jalan ditentukan oleh bentuk jalan pada suatu wilayah. Terdapat beberapa pola jaringan jalan di antaranya tidak teratur, radial konsentris, grid atau pola jalan bersiku, linear dan tidak berpola. Pada analisis pola jaringan jalan ditentukan melalui bentuk fisik berupa lebar dan arah jalan. Sebagian besar pola jaringan jalan pada Kota Surakarta dan wilayah peri urban berupa pola grid.

Pola grid atau pola jalan bersiku adalah pola jalan yang terbagi menjadi blok-blok persegi panjang dengan jalan paralel longitudinal dan transversal yang membentuk sudut siku-siku (Yunus, 2000). Jaringan jalan pada Kota Surakarta dan wilayah peri urban terdiri dari arteri dan kolektor sebagai klasifikasi jaringan jalan utama, serta jalan lokal dan jalan lingkungan sebagai 
klasifikasi jaringan jalan pendukung. Pola grid teridentifikasi melalui jalan kolektor dan jalan lokal yang kemudian membentuk pola siku-siku. Jaringan jalan tersebut memiliki dimensi atau ukuran lebar yang beragam, yaitu arteri dengan lebar $16 \mathrm{~m}$, kolektor dengan lebar 8-7 m, lokal dengan lebar $6 \mathrm{~m}$ dan jalan lingkungan dengan lebar $4 \mathrm{~m}$. Pola jalan grid memiliki keteraturan dalam membentuk sudut siku-siku pada pola jalan. Pola jaringan jalan Kota Surakarta dan wilayah peri urban memiliki pola yang sama yaitu berupa pola grid. Pola ini teridentifikasi dari pola jalan yang ada di Kota Surakarta dan wilayah peri urban. Keduanya memiliki pola jaringan jalan yang serupa. Hal ini bisa menunjukkan bahwa Kota Surakarta sebagai kota induk memberikan dampak yang sangat besar ke wilayah pinggirannya. Wilayah peri urban sendiri menjadi wilayah yang sangat terdampak dari kota induk yakni Kota Surakarta.

Walaupun sebagian besar pola yang terbentuk adalah pola grid, tetapi dapat dilihat melalui Gambar 4, bahwa terdapat pola tidak teratur yaitu pada jalan arteri. Sedangkan untuk jalan kolektor dan lokal, pola yang terbentuk lebih teratur. Dari peta dapat juga dilihat perbedaan pola jaringan jalan antara Kota Surakarta dan wilayah peri urban. Kota Surakarta walaupun memiliki pola grid yang terbentuk pada jaringan jalan kolektor, jalan lokal dan jalan lingkungan tetapi terlihat hampir seperti tidak beraturan. Hal ini bisa jadi dikarenakan tingginya kompleksitas Kota Surakarta sebagai kota induk. Sedangkan untuk wilayah peri urban pola grid dapat terlihat dengan jelas. Pola grid sangat terlihat jelas pada jalan kolektor, baik itu di Kota Surakarta maupun di wilayah peri urban. Pola grid yang terbentuk memiliki sudut siku-siku yang sangat jelas.

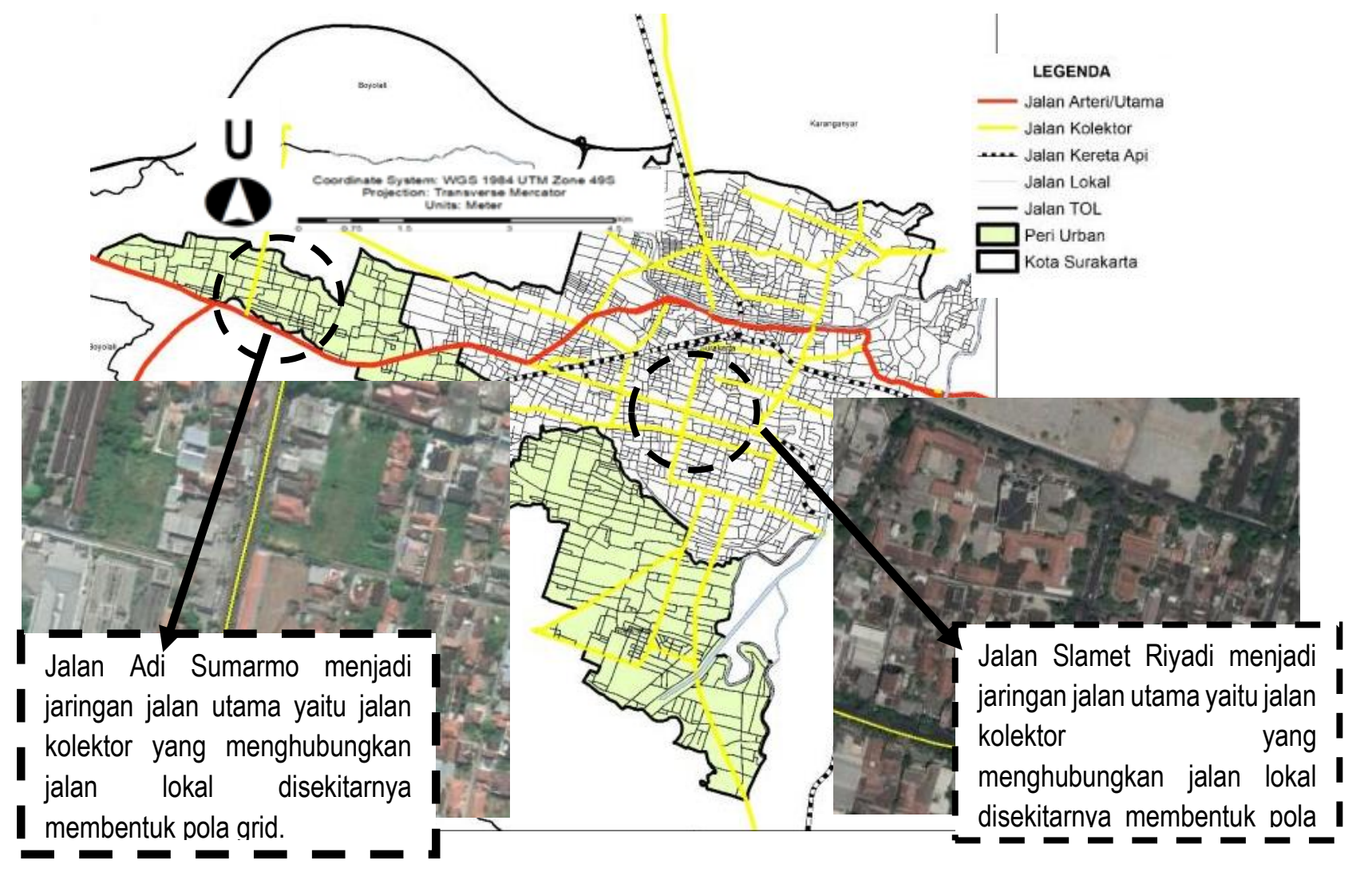

Gambar 4. Pola Jaringan Jalan Kota Surakarta dan Wilayah Peri Urban

Pola bangunan ditinjau dari kumpulan bangunan yang tersusun membentuk pola atau bentuk tertentu. Pola bangunan biasanya dilihat melalui kumpulan bangunan pada suatu wilayah, kumpulan bangunan ini nantinya akan ditinjau apakah membentuk suatu pola atau bentuk tertentu. Suatu pola atau bentuk tertentu ini nantinya digunakan untuk meninjau tekstur kawasan yang ada pada wilayah tersebut. Pada Kota Surakarta dapat dilihat bahwa sebagian besar wilayah kota dipenuhi dengan bangunan. Pada Gambar 5 dapat dilihat peta persil bangunan Kota Surakarta hampir keseluruhan wilayah berwarna abu-abu. Dari sini dapat dilihat minimnya ketersediaan lahan di Kota Surakarta yang memberikan dampak pada wilayah peri 
urban di sekitarnya. Bangunan yang ada pada Kota Surakarta sebagian besar adalah rumah kemudian baru bangunanbangunan seperti gedung, bangunan cagar budaya (istana keraton).

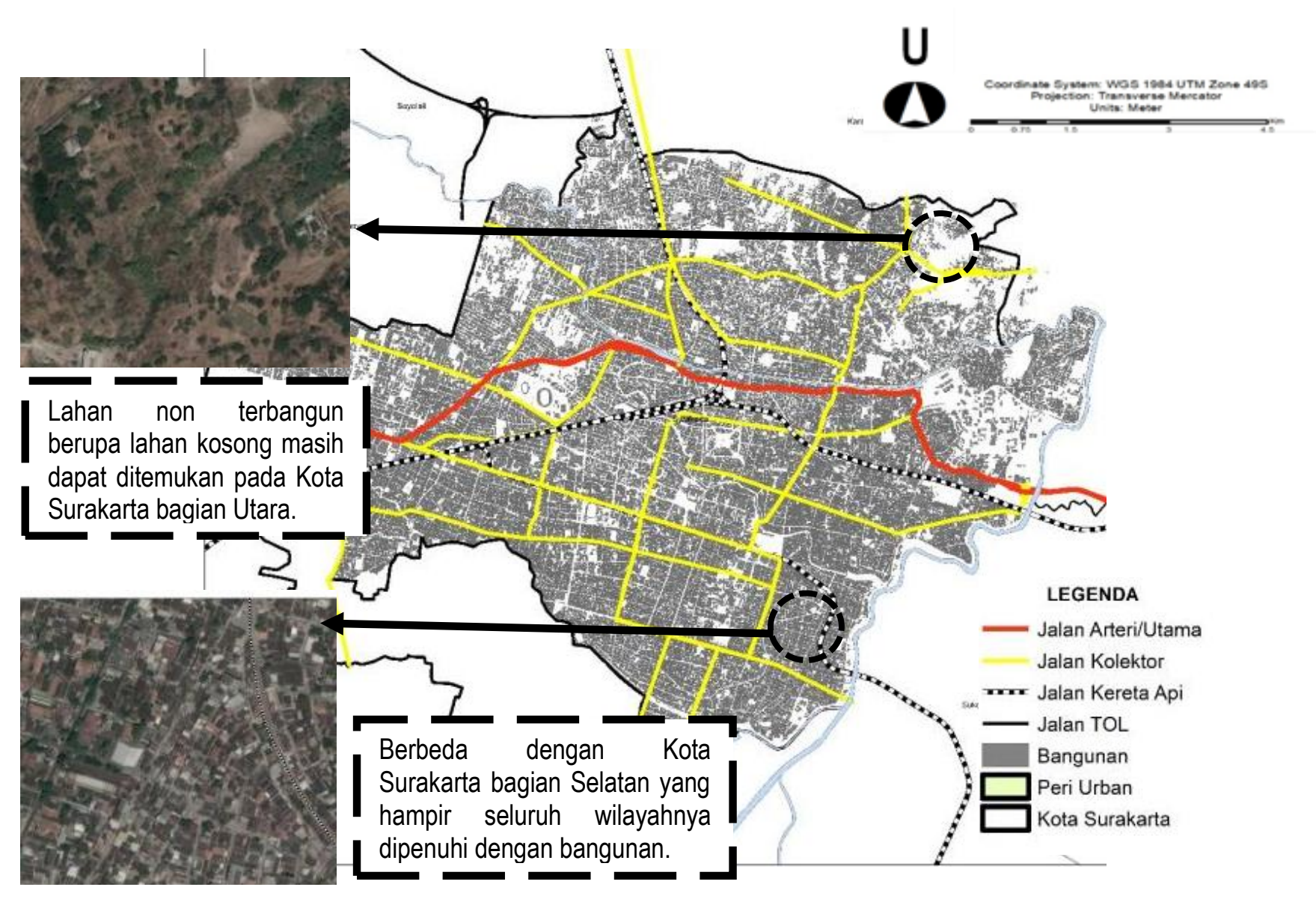

\section{Gambar 5. Sebaran Bangunan Kota Surakarta}

Sebaran bangunan pada Kota Surakarta merata pada seluruh wilayah kota. Meskipun pada bagian Utara dan Selatan terdapat perbedaan yaitu pada bagian Utara masih terdapat lahan kosong yang berpotensi untuk berubah menjadi lahan terbangun, sedangkan pada bagian Selatan cenderung padat oleh bangunan yang sebagian besar teridentifikasi sebagai rumah. Pada penggunaan lahan Kota Surakarta bagian Selatan dominasinya juga berupa permukiman.

Berbeda dengan pola bangunan pada wilayah peri urban yang cenderung masih menyebar karena masih tersedianya lahan non terbangun atau ruang terbuka hijau. Bangunan yang ada pada wilayah peri urban juga cenderung berupa rumah, tetapi yang membedakan dengan Kota Surakarta adalah adanya bangunan-bangunan pabrik dengan skala yang cukup besar. Dapat dilihat dari peta, kerapatan bangunan-bangunan pada wilayah peri urban cenderung berada pada jaringan jalan utama. Kerapatan bangunan-bangunan tersebut cukup tinggi jika dilihat dari warna abu-abu yang tergambar pada peta. Tidak hanya pada jaringan jalan utama, kerapatan bangunan juga dapat terlihat pada bagian perbatasan administrasi Kota Surakarta. Pada wilayah-wilayah perbatasan administrasi kota ini dominasi fungsi bangunan yang ada adalah rumah. Hal ini menunjukkan bahwa terjadi perluasan kenampakan fisik kekotaan pada wilayah peri urban. Selain rumah, terdapat juga beberapa sarana dengan skala regional yang berada pada wilayah perbatasan administrasi kota dan masuk ke dalam wilayah peri urban, di antaranya Universitas Muhammadiyah Surakarta (UMS), Rumah Sakit Ortopedi Dr. Soeharso, Rumah Sakit UNS, Transmart Pabelan, Al Firdhaus World Class Islamic School (AFWCIS).

Dari gambar 6 yang merupakan peta sebaran bangunan pada wilayah peri urban dapat dilihat bagaimana tekstur kawasan terbentuk: 


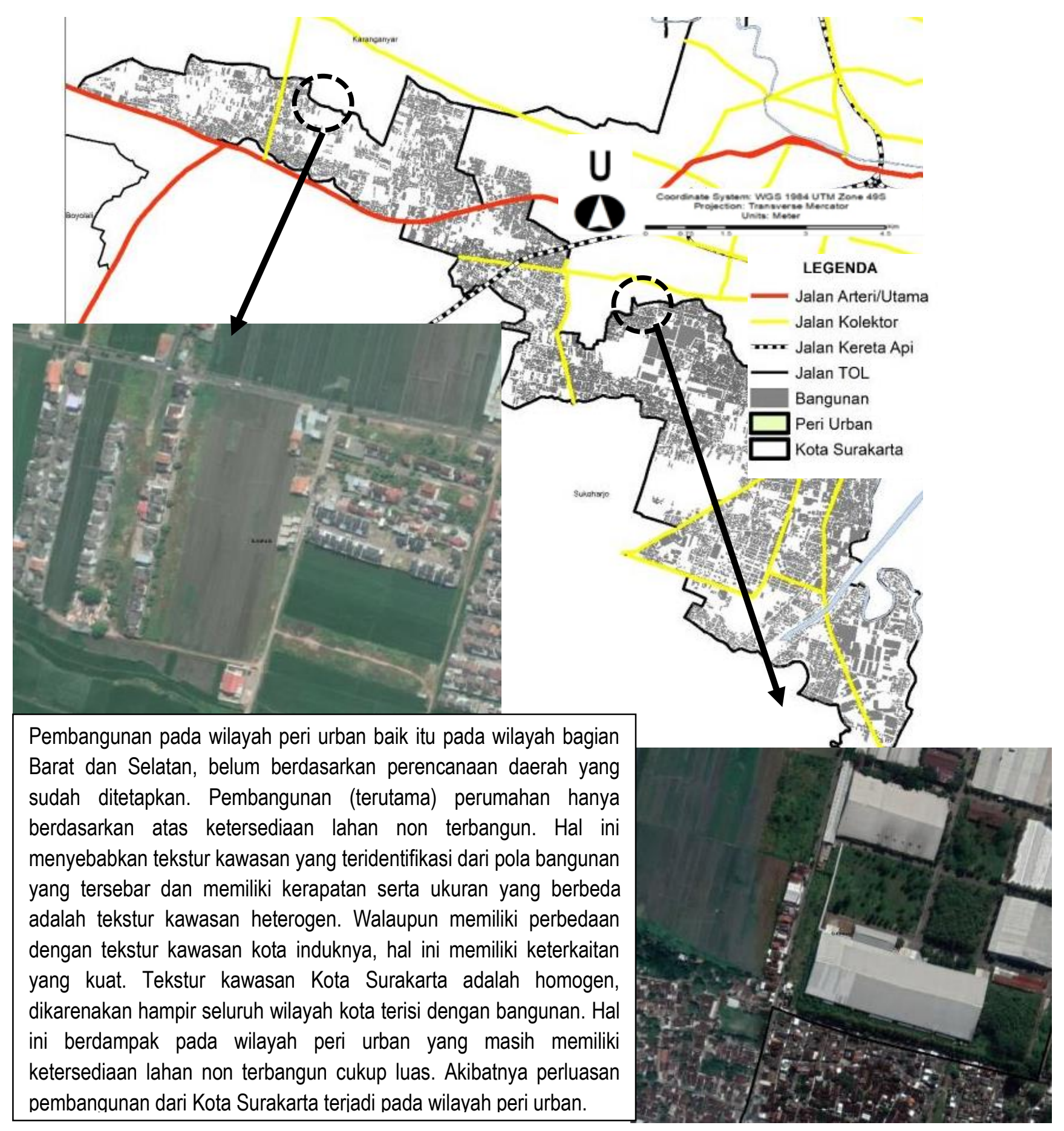

Gambar 6. Sebaran Bangunan Wilayah Peri Urban

\subsection{ANALISIS POLA MORFOLOGI}

Pola morfologi Kota Surakarta dan wilayah peri urban di sekitarnya ditinjau berdasarkan komponen morfologi yang teridentifikasi. Ditinjau dari penggunaan lahan eksisting, dominasinya berupa permukiman baik itu pada Kota Surakarta maupun wilayah peri urban. Hal ini menunjukkan adanya keterkaitan yang erat antara wilayah peri urban dan Kota Surakarta. Wilayah peri urban menjadi wilayah yang terdampak secara langsung dengan adanya perkembangan Kota Surakarta. Karena perkembangan suatu kota dapat dilihat dari peningkatan pertumbuhan penduduk, dengan adanya pertumbuhan penduduk ini 
maka selaras juga dengan meningkatnya kebutuhan akan lahan yang dijadikan sebagai tempat tinggal. Peningkatan kebutuhan lahan yang tidak sebanding dengan ketersediaan lahan pada suatu kota akan menyebabkan wilayah pinggiran menjadi pilihan kedua. Pada wilayah peri urban terutama wilayah yang berbatasan dengan administrasi kota memiliki penggunaan lahan sebagai permukiman. Walaupun terdapat perbedaan di antara kedua wilayah bagian peri urban. Jika pada wilayah peri urban bagian Selatan, penggunaan lahan sebagai industri jauh lebih banyak jika dibandingkan dengan wilayah peri urban bagian Barat. Pada wilayah peri urban bagian Barat juga masih dapat ditemui beberapa industri, tetapi untuk industri-industri skala besar berada pada wilayah peri urban bagian Selatan. Untuk penggunaan lahan sebagai perdagangan dan jasa sebagian besar mengikuti pola jaringan jalan yang ada, baik itu pada Kota Surakarta maupun pada wilayah peri urban. Tetapi tidak hanya mengikuti pola jaringan jalan, terdapat juga penggunaan lahan sebagai perdagangan dan jasa yang tersebar. Pada penggunaan lahan lain-lain pada wilayah peri urban bagian Barat teridentifikasi sebagai sebagai perguruan tinggi, rumah sakit, dan pusat perbelanjaan (mall).

Pola jaringan jalan yang teridentifikasi pada Kota Surakarta dan wilayah peri urban sebagian besar adalah berupa pola grid. Pola jalan berbentuk siku-siku hampir mendominasi seluruh pola jaringan jalan Kota Surakarta dan wilayah peri urban, kecuali jaringan jalan arteri yang memiliki pola tidak teratur. Pola jaringan jalan terlihat memberikan pengaruh sangat besar terhadap perkembangan Kota Surakarta dan wilayah peri urban. Hal ini dapat dilihat dari penggunaan lahan perdagangan jasa yang cenderung mengikuti jaringan jalan. Pada identifikasi pola bangunan, terdapat perbedaan tekstur kawasan antara Kota Surakarta dengan wilayah peri urban. Hal ini dikarenakan terdapat perbedaan kerapatan, massa ruang dan ukuran pada Kota Surakarta dan wilayah peri urban. Pada Kota Surakarta yang cenderung pada tekstur kawasan homogen sedangkan pada wilayah peri urban cenderung pada tekstur kawasan heterogen. Dari ketiga komponen tersebut, pola morfologi yang paling mendekati untuk wilayah peri urban terhadap Kota Surakarta adalah bentuk pita. Dimana indikator dari bentuk pita adalah memiliki pola jaringan jalan grid dan memiliki tekstur kawasan heterogen. Dalam indikator bentuk pita, pola bangunan yang menjadi acuan adalah pola bangunan yang mengikuti pola jaringan jalan. Pada wilayah peri urban kecenderungan dari penggunaan lahan, dan pola bangunan lebih condong ke arah jalur transportasi atau mengikuti pola jaringan jalan. Hal ini dirasa sesuai dengan indikator awal bentuk pita. Dapat dilihat dari Tabel 3, kondisi eksisting jika dikaitkan dengan indikator bentuk morfologi adalah sebagai berikut:

Tabel 3. Analisis Bentuk dan Komponen Morfologi

\begin{tabular}{|c|c|}
\hline Komponen & Analisis \\
\hline $\begin{array}{l}\text { Penggunaan } \\
\text { Lahan }\end{array}$ & $\begin{array}{l}\text { Terdapat persamaan dominasi dan pola penggunaan lahan pada Kota Surakarta dan wilayah peri urban. Dominasi } \\
\text { penggunaan lahan berupa permukiman dan pola perdagangan dan jasa yang mengikuti jaringan jalan. Dapat dikatakan } \\
\text { bahwa Kota Surakarta memiliki pengaruh besar terhadap wilayah peri urban. Tetapi terdapat juga perbedaan yang } \\
\text { signifikan, dimana ketersediaan RTH pada Kota Surakarta sangat minim sedangkan pada wilayah peri urban cukup } \\
\text { luas. Perbedaan selanjutnya pada penggunaan lahan industri yang banyak ditemukan pada wilayah peri urban terutama } \\
\text { pada bagian Selatan. }\end{array}$ \\
\hline $\begin{array}{l}\text { Pola Jaringan } \\
\text { Jalan }\end{array}$ & $\begin{array}{l}\text { Kesamaan pola jaringan jalan pada Kota Surakarta dan wilayah peri urban menunjukkan adanya keterkaitan kota induk } \\
\text { dengan wilayah pinggirannya. Tetapi perbedaan yang cukup jelas adalah kerapatan jalan pada Kota Surakarta } \\
\text { cenderung jauh lebih rapat daripada wilayah peri urban. Hal ini disebabkan terbatasnya lahan non terbangun pada Kota } \\
\text { Surakarta. Sedangkan pada wilayah peri urban masih tersedia cukup banyak jadi tingkat kerapatan pola jaringan jalan } \\
\text { seperti Kota Surakarta. }\end{array}$ \\
\hline $\begin{array}{l}\text { Pola } \\
\text { Bangunan }\end{array}$ & $\begin{array}{l}\text { Berdasarkan dari kondisi eksisting pola sebaran bangunan pada Kota Surakarta dan wilayah peri urban terdapat } \\
\text { perbedaan, hal ini menyebabkan terjadinya perbedaan tekstur kawasan yang teridentifikasi. Pada Kota Surakarta } \\
\text { tekstur kawasan yang teridentifikasi adalah homogen dengan persebaran merata ke seluruh wilayah. Sedangkan pada } \\
\text { wilayah peri urban, tekstur kawasan yang teridentifikasi adalah heterogen. Pola sebaran bangunan pada wilayah peri } \\
\text { urban cenderung mengikuti pola jaringan jalan dan tidak memiliki pusat kawasan jika ditinjau dari penggunaan lahan. }\end{array}$ \\
\hline
\end{tabular}

Dari data tabel 3, apabila dituangkan ke dalam bentuk peta terlihat seperti pada gambar di bawah ini. Pola morfologi kota sedang (Kota Surakarta) dan wilayah peri urban terdapat perbedaan dikarenakan kondisi eksisting. Pada Kota Surakarta, lahan non terbangun yang tersedia sudah sangat minim, berbeda dengan wilayah peri urban. Perkembangan Kota Surakarta sudah meluas ke seluruh bagian kota, hal ini menyebabkan terjadinya perkembangan pada wilayah peri urban. Pada wilayah peri urban, perkembangan wilayah cenderung hanya mengikuti kondisi ketersediaan lahan non terbangun yang ada, sehingga menyebabkan persebaran pembangunan cenderung belum merata, ditambah masih tersedianya lahan non terbangun yang cukup luas dibandingkan dengan Kota Surakarta. 


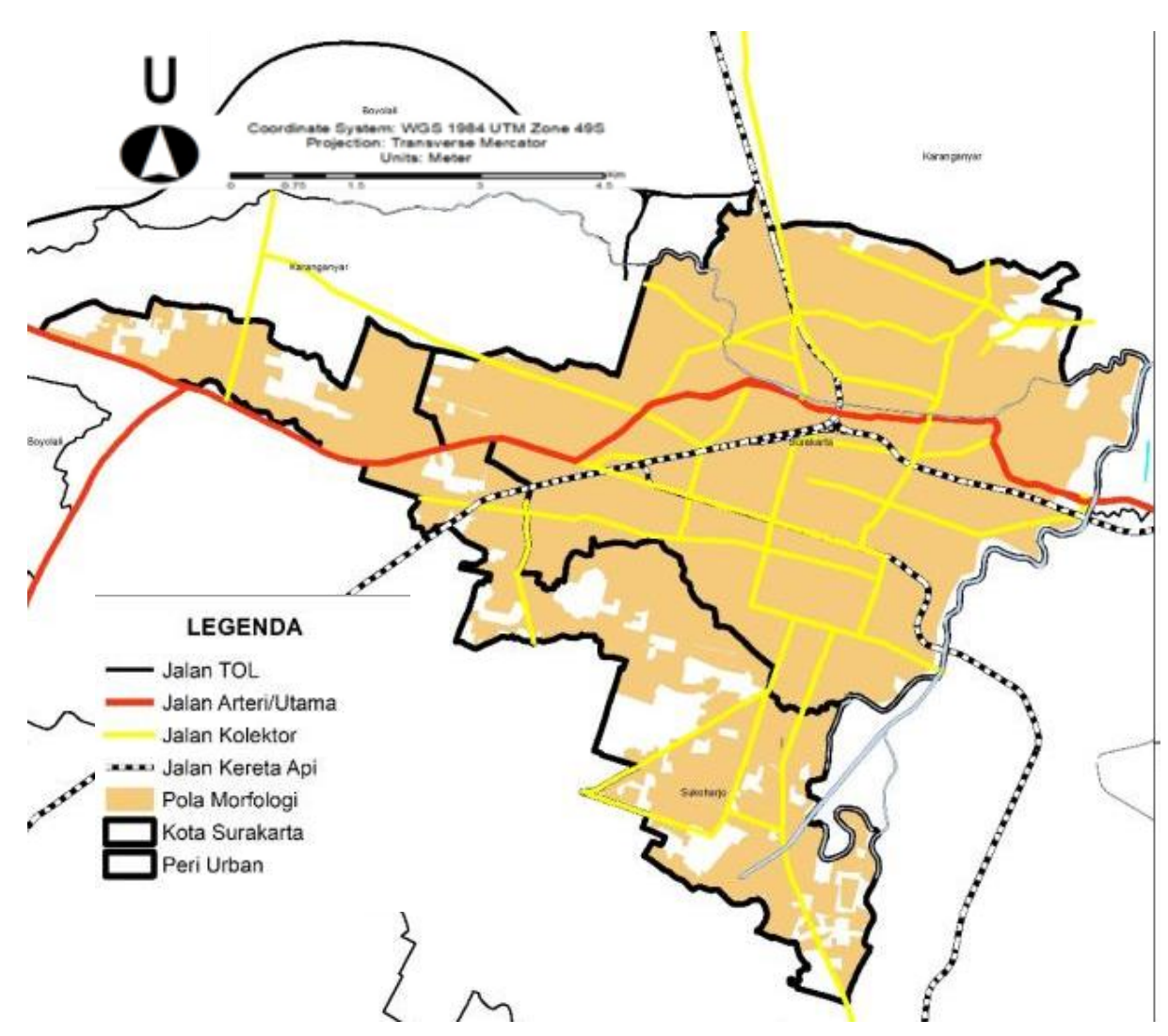

Gambar 7. Pola Morfologi Kota Surakarta Dan Wilayah Peri Urban di Sekitarnya

\section{KESIMPULAN}

Wilayah peri urban yang teridentifikasi dari delineasi empat kriteria adalah pada bagian Barat dan Selatan Kota Surakarta. Berdasarkan hasil observasi komponen morfologi pada Kota Surakarta dan wilayah peri urban, terdapat persamaan pada dominasi penggunaan lahan dan pola jaringan jalan. Dominasi penggunaan lahan pada Kota Surakarta dan wilayah peri urban berupa permukiman, sedangkan pola jaringan jalan yang mendominasi adalah pola grid. Terdapat perbedaan pada tekstur kawasan Kota Surakarta dan wilayah peri urban. Kota Surakarta yang hampir $90 \%$ luas wilayahnya sudah terbangun memiliki tekstur kawasan homogen, karena memiliki kerapatan dan persebaran bangunan yang merata ke seluruh wilayah kota. Sedangkan pada wilayah peri urban memiliki tekstur kawasan heterogen, hal ini disebabkan oleh kerapatan dan persebaran bangunan yang cenderung menyebar dikarenakan masih tersedianya lahan non terbangun yang cukup luas. Dari ketiga komponen ini, Kota Surakarta dan wilayah peri urban memiliki pola morfologi yang berbeda. Pola morfologi Kota Surakarta adalah bujur sangkar, karena perkembangan terjadi pada hampir seluruh wilayah kota. Sedangkan pada wilayah peri urban pola yang terbentuk dari perkembangan Kota Surakarta adalah pita, karena perkembangan terjadi cenderung mengikuti pola jaringan jalan utama dan didukung dengan ketersediaan lahan non terbangun yang cukup.

\section{DAFTAR PUSTAKA}

Astutik, I., Tallo, A. J., \& Pratiwi, Y. (2014). Identifikasi Pola Morfologi Kota (Studi Kasus : Sebagian Kecamatan Klojen, Di Kota Malang), Jurnal Perencanaan Wilayah dan Kota, 25(3), 213-227.

Badan Pusat Statistik Kabupaten Boyolali. (2013). Kecamatan Ngemplak Dalam Angka Tahun 2013. Diakses dari https://boyolalikab.bps.go.id/publication/2013/12/24/5038ef98db233ec8e4e333ad/kecamatan-ngemplak-dalam-angka-2013.html

Badan Pusat Statistik Kabupaten Boyolali. (2018). Kecamatan Ngemplak Dalam Angka Tahun 2018. Diakses dari https://boyolalikab.bps.go.id/publication/2018/09/26/d689ed53fe2f2ba7b4a0128e/kecamatan-ngemplak-dalam-angka-2018.html 
Desa-Kota, Vol. 2, No. 2, 2020, 130-142

Badan Pusat Statistik Kabupaten Sukoharjo. (2014). Kecamatan Baki Dalam Angka Tahun 2013. Diakses dari https://sukoharjokab.bps.go.id/publication/2014/02/24/445aa212b56859aedd578630/kecamatan-baki-dalam-angka-2013.html

Badan Pusat Statistik Kabupaten Sukoharjo. (2014). Kecamatan Gatak Dalam Angka Tahun 2013. Diakses dari https://sukoharjokab.bps.go.id/publication/2014/02/24/882a87bae83730e35b7486ef/kecamatan-gatak-dalam-angka-2013.html

Badan Pusat Statistik Kabupaten Sukoharjo. (2014). Kecamatan Grogol Dalam Angka Tahun 2013. Diakses dari https://sukoharjokab.bps.go.id/publication/2014/02/24/ce39995c7dee5e28562a47aa/kecamatan-grogol-dalam-angka-2013.html

Badan Pusat Statistik Kabupaten Sukoharjo. (2014). Kecamatan Kartasura Dalam Angka Tahun 2013. Diakses dari https://sukoharjokab.bps.go.id/publication/2014/02/24/d10606f99babcfb870d3fdeb/kecamatan-kartasura-dalam-angka-2013.html

Badan Pusat Statistik Kabupaten Sukoharjo. (2018). Kecamatan Baki Dalam Angka Tahun 2018. Diakses dari https://sukoharjokab.bps.go.id/publication/2018/09/26/d82bab3cc88df8db4d8afab5/kecamatan-baki-dalam-angka-2018.html

Badan Pusat Statistik Kabupaten Sukoharjo. (2018). Kecamatan Gatak Dalam Angka Tahun 2018. Diakses dari https://sukoharjokab.bps.go.id/publication/2018/09/26/f0fd503767b8b5c2f7bfb9fo/kecamatan-gatak-dalam-angka-2018.html

Badan Pusat Statistik Kabupaten Sukoharjo. (2018). Kecamatan Grogol Dalam Angka Tahun 2018. Diakses dari https://sukoharjokab.bps.go.id/publication/2018/09/26/3be2c13b67ade8715499ef65/kecamatan-grogol-dalam-angka-2018.html

Badan Pusat Statistik Kabupaten Sukoharjo. (2018). Kecamatan Kartasura Dalam Angka Tahun 2018. Diakses dari https://sukoharjokab.bps.go.id/publication/2018/09/26/06beea2db9250f2144673f52/kecamatan-kartasura-dalam-angka-2018.html

Hardati, P. (2011). Transformasi Wilayah Peri Urban (Studi Kasus : Kabupaten Semarang), Jurnal Geografi, 8(2), 108-117. Diakses dari https://journal.unnes.ac.id/nju/index.php/JG/article/view/1661/1868

Jati, V. I. M. \& Christanto, J. (2012). Kajian Perkembangan Permukiman Wilayah Peri Urban Di Sebagian Wilayah Kabupaten Sukoharjo Tahun 2001-2007, Jurnal Bumi Indonesia 1(1), 1-8. Diakses dari http:/lib.geo.ugm.ac.id/ojs/index.php/jbi/article/view/58

Krismasta, V., Rogi, O. H., \& Tilaar, S. (2014). Kajian Transformasi Wilayah Peri Urban Di Kota Manado (Studi Kasus : Kecamatan Mapanget), Jurnal Spasial: Perencanaan Wilayah dan Kota, 2(1), 1-9. Diakses dari https://ejournal.unsrat.ac.id/index.php/spasial/article/view/8260/7819

Kurnianingsih, N. A., \& Rudiarto, I. (2014). Analisis Transformasi Wilayah Peri Urban Pada Aspek Fisik Sosial Ekonomi (Kecamatan Kartasura), Jurnal Pembangunan Wilayah Dan Kota, 10(3), 265-277. DOI: 10.14710/pwk.v10i3.7784

Putri, M. A., Rahayu, M. J., \& Putri, R. A. (2016). Bentuk Kenampakan Fisik (Morfologi) Kawasan Permukiman di Wilayah Pinggiran Selatan Kota Surakarta, Jurnal Pengembangan Kota, 4(2), 120-128. DOI: 10.14710/jpk.4.2.120-128

Soetomo, S. (2009). Urbanisasi dan Morofologi. Yogyakarta: Graha IImu.

Sugiyono. (2010). Metode Penelitian Kuantitatif, Kualitatif dan R\&D. Bandung: CV. Alfabeta.

Sushanti, I. R., Imansyah, N. H., Susanti, F., Mahendra, Y. I., \& Ridha, R. (2018). Kajian Perubahan Fisik Spasial Kawasan Urban Fringe Kecamatan Ampenan Kota Mataram, Jurnal Planoearth, 3(2), 44-48. DOI: 10.31764/jpe.v3i2.609

Tyas, W. I., Danial, D. M., \& Izjrail, A. B. (2013). Kajian Bentuk dan Tatanan Massa Di Kawasan Bangunan Ci-Walk (Cihampelas Walk), Jurnal Reka Karsa, 1(2). Diakses dari https://ejurnal.itenas.ac.id/index.php/rekakarsa/article/view/262

Yunus, H. S. (2000). Struktur Tata Ruang Kota. Yogyakarta: Pustaka Pelajar.

Yunus, H. S. (2008). Dinamika Wilayah Peri Urban. Yogyakarta: Pustaka Pelajar. 